\title{
Incidence and risk factors for surgical site infection post-gynecological operations in a tertiary hospital in Egypt: a retrospective study
}

\author{
Khaled Goma $^{1}$, Saad El Gelany ${ }^{1 *}$, Ahmed Fawzy Galal ${ }^{2}$ \\ ${ }^{1}$ Department of Obstetrics and Gynecology, Faculty of Medicine, Minia University, Egypt \\ ${ }^{2}$ Department of Obstetrics and Gynecology, Faculty of Medicine, Alexandria University, Egypt
}

Received: 22 December 2021

Accepted: 06 January 2022

*Correspondence:

Saad El Gelany,

E-mail: Saad.Elgelany@mu.edu.eg

Copyright: () the author(s), publisher and licensee Medip Academy. This is an open-access article distributed under the terms of the Creative Commons Attribution Non-Commercial License, which permits unrestricted non-commercial use, distribution, and reproduction in any medium, provided the original work is properly cited.

\begin{abstract}
Background: Surgical site infection (SSI) is the most common complication of surgical procedures in gynecology and it poses a significant burden for both patients and healthcare systems. Our objective was determining the incidence and risk factors for SSI post-gynecological operations during the period of five years.

Methods: A matched case-control study at Minia maternity university, Egypt where A total of 18772 cases had undergone different gynecological procedures. The 876 cases were complicated with SSI (SSI cases group) and 2 matched controls per case were chosen from the rest of the cases and served as the control group ( $\mathrm{n}=1752$ cases).

Results: The overall incidence of SSI post-gynecological operations was $4.67 \%$ and post-hysterectomy was $7.57 \%$. SSI group had a significantly higher number of cases with diabetes, obesity, high parity $(>4)$, increased blood loss and those had prolonged duration of surgery compared to the control group (all $\mathrm{p}<0.01$ ).

Conclusions: The identified risk factors are crucial for risk stratification of SSI and prioritizing interventions to improve the outcome. These results could give a picture for SSI post-gynecological operations in our country and identifying these risk factors is crucial for risk stratification of SSI and prioritizing interventions to improve the outcome.
\end{abstract}

Keywords: SSI, Gynecological operations, Incidence, Risk factors

\section{INTRODUCTION}

In gynecological operations, the most common complication of surgical procedures is a SSI and it poses a significant burden for patients, their families and healthcare systems. ${ }^{1}$ SSI can cause serious morbidity and mortality, as well as prolonged hospitalization and high financial expenses for patients and healthcare systems. ${ }^{2}$ Patients with SSI are twice as likely to die, $60 \%$ more likely to spend time in an intensive care unit, and more than five times more likely to be readmitted to the hospital than those who do not. ${ }^{3}$

Following caesarean delivery, hysterectomy is the most common gynecologic surgical treatment and the second most commonly performed major surgery for women of reproductive age. ${ }^{1}$ Potential pathogenic microorganisms may enter the surgical site through the epidermis or rise from the vaginal and endocervix, causing vaginal cuff cellulitis, pelvic cellulitis, and pelvic abscesses. ${ }^{4}$ The risk of SSI development in the abdominal hysterectomy was significantly higher than that of the vaginal hysterectomy. ${ }^{5}$

Controversial results were published regarding the incidence of SSI post-gynecological surgeries. Gynecological surgeries have similar SSI rates as other surgical procedures in developed countries. and it was reported that the SSI rates are high in low and middleincome countries compared to high-income ones. ${ }^{6}$ The incidence of SSI was $3.9 \%$ for open hysterectomy and $1.4 \%$ for minimally invasive procedures. ${ }^{7}$ Recently, it was estimated that the incidence of SSI in low and middleincome countries was $11.8 \%$. In addition, a recent Indian study reported that the incidence of SSI rate was $10.3 \%$ 
post-gynecological surgeries, $11.6 \%$ for vaginal hysterectomy and 3.79 percentage for the abdominal hysterectomy. ${ }^{5}$

In gynecologic surgery "particularly hysterectomy", SSI was associated with many risk factors that may or may not be modifiable strand $2017 .{ }^{8}$ These risk factors include; preoperative factors such as vaginal examinations before surgery or presence of vaginal discharge, co-morbid conditions or medical diseases like diabetes mellitus, hypertension, anemia, renal, cardiac disease and liver disease in addition to the requirement of blood transfusion before surgery and the bad American society of anesthesia (ASA). ${ }^{2,9}$ SSI is linked to intraoperative risk factors such as; emergency or nonemergency surgery, excessive bleeding, prolonged surgical operative time and blood transfusion. ${ }^{9,10}$ Simultaneous efforts to determine the rates of SSI post-gynecological surgeries and identifying its associated risk factors is crucial and could help to increase the awareness among the health care professionals for risk stratification of SSI and prioritizing interventions to improve the outcome. So, the aim of this study is to determine the prevalence and risk factors for SSI following gynaecological procedures in the Egyptian tertiary hospital.

\section{METHODS}

\section{Study settings}

This is a matched case-control study (2 controls per case, matched on date of surgery) carried out at Minia maternity university hospital, Egypt (a tertiary referral hospital) during the period of five years from January 2013 to December 2017.

\section{Study population}

A total of 18772 cases had undergone different gynecological operations and procedures $(23.3 \%$ hysterectomy, $11.6 \%$ myomectomy, $23.0 \%$ ectopic pregnancy, $20.6 \%$ laparoscopy, $6.8 \%$ sling operation and $14.6 \%$ ovarian swelling) during the study period (5 years). Of these cases, 876 cases were complicated with SSI and we included them in the study as SSI cases group and we have chosen 2 matched controls per case (on the date of surgery) from the rest of the cases served as the control group ( $n=1752$ cases). SSI was based on the definition proposed by the centers for disease control and prevention (CDC) guidelines. ${ }^{11}$

A well-trained worker used a specific Proforma to collect data from medical records (including in-patients and operating room records). Each case's demographic, clinical, and obstetric data were documented, including age, parity, residency, and medical co-morbidities such as diabetes and hypertension etc. Also, duration of surgery, blood loss, use of antibiotics and duration of hospital stay were recorded.

\section{Statistical analysis}

Statistical analysis was performed using SPSS program (version 20). Categorical data were expressed as no. (\%) while, continuous data were expressed as mean and standard deviation (SD). Chi-square test was used to compare between the two groups regarding categorical variables while an independent sample t test was used for continuous variables. Odds ratios and $95 \%$ confidence intervals (CI) were calculated. Univariate and multivariate logistic regression analyses were used for the determination of risk factors associated with SSI. A probability value of $<0.05$ was considered significant, and that of $<0.01$ was considered highly significant.

\section{RESULTS}

A total of 876 cases developed SSI during the study period so, the overall incidence of SSI post-gynecological operations was $4.67 \% \quad(876 / 18772)$ (Figure 1). Hysterectomy contributed $23.3 \%$ of the undergone gynecologic procedures (4371 cases) and the rate of SSI in these cases was $7.57 \%$ (331 cases). No significant differences were observed between SSI and control groups regarding age $(p=0.13)$ and residence $(p=0.22)$ while, the percentage of cases with high parity $(>4)$ was significantly higher in SSI group compared to control group (18.3 vs. $14.2 \%, \mathrm{p}<0.01)$. Obesity was more prevalent in SSI group than the control one $(21.9 \%$ vs. $11.5 \%, \mathrm{p}<0.01$, $\mathrm{COR}=2.17)$. The results revealed that SSI was significantly associated with diabetes mellitus (14.0\% in SSI group vs. $5.0 \%$ in control group, $\mathrm{p} \leq 0.01, \mathrm{COR}=3.13$ ), prolonged duration of surgery $(23.3 \%$ in SSI group vs. $6.7 \%$ in control group, $\mathrm{p} \leq 0.01, \mathrm{COR}=4.24)$, high blood loss $(17.6 \%$ in SSI group vs. $3.5 \%$ in control group, $\mathrm{p} \leq 0.01, \mathrm{COR}=5.91)$ and no use of antibiotics $(33.6 \%$ in $\mathrm{SSI}$ group vs. $22.7 \%$ in control group, $\mathrm{p} \leq 0.01, \mathrm{COR}=1.72$ ) while, there was no association between SSI and hypertension $(\mathrm{p}=0.68, \mathrm{COR}=0.90)$ (Table 1$)$.

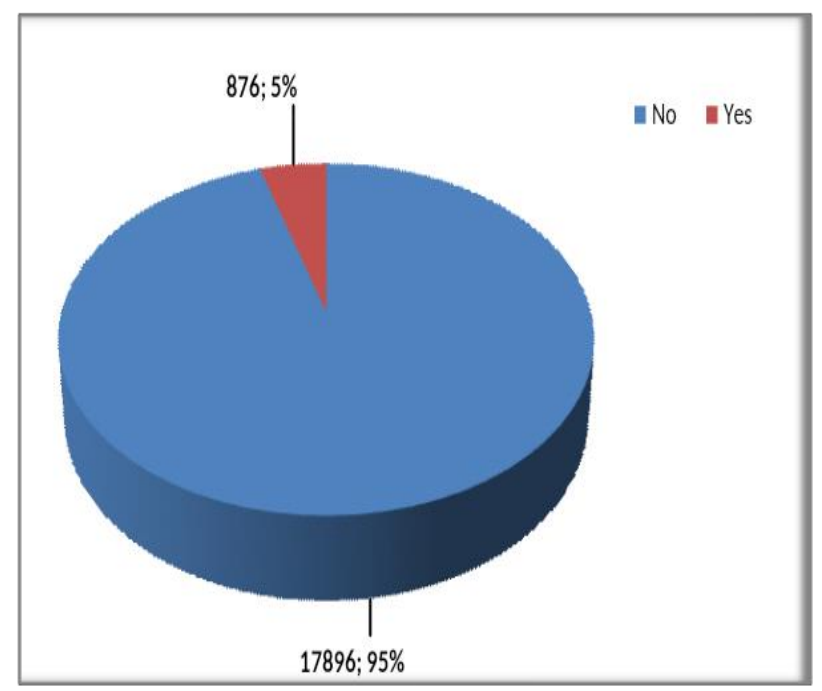

Figure 1: Incidence of SSI post different gynecological operations during the study period. 
Table 1: Baseline and obstetric data between SSI and control groups.

\begin{tabular}{|c|c|c|c|c|c|}
\hline Variables & $\begin{array}{l}\text { SSI group, } \\
(n=876)(\%)\end{array}$ & $\begin{array}{l}\text { Control group, } \\
(n=1752)(\%)\end{array}$ & $\chi^{2}$ & P. V. (Sig.) & $\begin{array}{l}\text { Crude odds ratio } \\
\text { (COR), (95\% CI) }\end{array}$ \\
\hline Age $($ Mean \pm SD $)($ years $)$ & $32.5 \pm 4.8$ & $32.2 \pm 4.7$ & $1.53^{\#}$ & $0.13^{\mathrm{NS}}$ & - \\
\hline \multicolumn{6}{|l|}{ Residence } \\
\hline Urban & $394(45)$ & $832(47.5)$ & 1.48 & $0.22^{\mathrm{NS}}$ & 1.0 \\
\hline Rural & $482(55)$ & $920(52.5)$ & & & $1.12(0.94-1.30)$ \\
\hline \multicolumn{6}{|l|}{ Parity } \\
\hline $1-4$ & $716(81.7)$ & $1503(85.8)$ & 7.30 & $\leq 0.01 * *$ & 1.0 \\
\hline$>4$ & $160(18.3)$ & $249(14.2)$ & & & $1.35(1.09-1.68)$ \\
\hline \multicolumn{6}{|l|}{ Obesity } \\
\hline No & $684(78.1)$ & $1551(88.5)$ & 50.1 & $\leq 0.01 * *$ & 1.0 \\
\hline Yes & $192(21.9)$ & $201(11.5)$ & & & $2.17(1.74-2.69)$ \\
\hline \multicolumn{6}{|l|}{ Diabetes mellitus } \\
\hline No & $753(86)$ & $1665(95)$ & 65.4 & $\leq 0.01 * *$ & 1.0 \\
\hline Yes & $123(14)$ & $87(5)$ & & & $3.13(2.34-4.17)$ \\
\hline \multicolumn{6}{|l|}{ Hypertension } \\
\hline No & $852(97.3)$ & $1699(97.30)$ & 0.17 & $0.68^{\mathrm{NS}}$ & 1.0 \\
\hline Yes & $24(2.7)$ & $53(3)$ & & & $0.90(0.55-1.47)$ \\
\hline \multicolumn{6}{|l|}{ Duration of surgery } \\
\hline Normal & $672(76.7)$ & $1635(93.3)$ & 150.1 & $\leq 0.01 * *$ & 1.0 \\
\hline Prolonged & $204(23.3)$ & $117(6.7)$ & & & $4.24(3.32-5.42)$ \\
\hline \multicolumn{6}{|l|}{ Blood loss (high) } \\
\hline No & $722(82.4)$ & $1691(96.5)$ & 154.5 & $\leq 0.01 * *$ & 1.0 \\
\hline Yes & $154(17.6)$ & $61(3.5)$ & & & $5.91(4.34-8.05)$ \\
\hline \multicolumn{6}{|l|}{ Use of antibiotic } \\
\hline No & $294(33.6)$ & $398(22.7)$ & 35.4 & $\leq 0.01 * *$ & $1.72(1.44-2.06)$ \\
\hline Yes & $582(66.4)$ & $1354(77.3)$ & & & 1.0 \\
\hline
\end{tabular}

Table 2: Multivariate analysis of risk factors for SSI.

\begin{tabular}{|lll|}
\hline Variables & Adjusted odds ratio (AOR), (95\% CI) & P. V. (Sig) \\
\hline Age ( $\geq$ 35 years) & $0.46(0.31-0.95)$ & $0.61^{\mathrm{NS}}$ \\
\hline Residence (rural) & $0.83(0.58-1.03)$ & $0.54^{\mathrm{NS}}$ \\
\hline Parity $(>\mathbf{4})$ & $1.18(1.01-1.65)$ & $0.04^{*}$ \\
\hline Obesity & $2.02(1.85-2.44)$ & $0.02^{*}$ \\
\hline Diabetes mellitus & $2.98(2.51-3.74)$ & $<0.01^{* *}$ \\
\hline Hypertension & $0.64(0.33-1.14)$ & $0.57^{\mathrm{NS}}$ \\
\hline Duration of surgery (prolonged) & $4.03(3.42-4.95)$ & $<0.01^{* *}$ \\
\hline Blood loss (high) & $4.95(4.12-5.84)$ & $<0.01^{* *}$ \\
\hline No use of antibiotic & $1.41(1.24-2.54)$ & $<0.01^{* *}$ \\
\hline
\end{tabular}

Results of the multivariate analysis of risk factors for SSI showed that high blood loss was the first significant one (AOR 4.95; 95\% CI=4.12-5.84; $\mathrm{p} \leq 0.01$ ) followed by prolonged duration of surgery (AOR 4.03; 95\% CI=3.42$4.95 ; \mathrm{p} \leq 0.01$ ), diabetes mellitus (AOR 2.98; 95\% CI=2.51$3.74 ; \mathrm{p} \leq 0.01$ ), obesity (AOR 2.02;95\% CI=1.85-2.44; $\mathrm{p} \leq 0.01$ ), no use of antibiotic (AOR $1.41 ; 95 \% \mathrm{CI}=1.24-$ $2.54 ; \mathrm{p} \leq 0.01)$ and high parity $(>4)$, (AOR 1.18; 95\% $\mathrm{CI}=1.01-1.56 ; \mathrm{p}=0.04$ ) (Table 2).

\section{DISCUSSION}

SSI remains the commonest complication of surgical procedures in gynecology and it poses a significant burden on both the mother and the health care system. ${ }^{1}$ Rates of
SSI can vary widely by type of procedure performed and by the approach used for a single procedure and many studies reported controversial findings regarding the rates of SSI. ${ }^{6}$ In gynecologic surgery (particularly hysterectomy), SSI was associated with many risk factors that may or may not be modifiable. ${ }^{8}$ To the best of our knowledge, almost no data were available about the incidence of SSI post-gynecologic operations and its related risk factors in Egypt. So, this study attempted to evaluate the incidence of SSI post-gynecological operations and its associated risk factors.

In this study, the overall incidence of SSI postgynecological operations was $4.67 \%$ and posthysterectomy was $7.57 \%$. Hysterectomy is the most 
common gynecological surgery for women of reproductive age. This rate is lower than that reported in a recent Indian study by Pathak et al who found that the overall rate of SSI was $10.3 \%$ post-gynecological surgeries, $11.6 \%$ for vaginal hysterectomy and $3.79 \%$ for abdominal hysterectomy..$^{5}$ Also, Davidson et al found that the rate of SSI after hysterectomy was $6.18 \% .^{12}$ In previous studies, it has been reported that laparoscopic hysterectomies had significantly lower SSI risks compared to open abdominal approaches. ${ }^{13}$ While, the obtained SSI incidence in this study was higher than that reported in other studies, the incidence of infection was estimated as $3.9 \%$ for open hysterectomy and $1.4 \%$ for minimally invasive procedures. $^{14}$ Also, Lake et al and POP-VICAS and colleagues studied the occurrence of SSI posthysterectomy and its associated risk factors and they found that the rate of SSI was around 3.0\%., The wide variation between studies in the rates of SSI was due to many factors such as grade of surgeon and surgical techniques, comorbidities and use of prophylactic antibiotics and when these factors were included in the studies, these variations in SSI rates become closer. In addition, sample size, setting, and duration variances between studies all play a role in these disparities.

In this study, SSI group had a significantly higher number of cases with high blood loss, diabetes, obesity, high parity (>4) and those who had prolonged duration of surgery compared to the control group. In addition, the results of the multivariate analysis of risk factors for SSI revealed that high blood loss was the first significant one (AOR $4.95, \mathrm{p} \leq 0.01$ ) followed by prolonged duration of surgery (AOR 4.03, $\mathrm{p} \leq 0.01$ ), diabetes mellitus (AOR $2.98 \mathrm{p} \leq 0.01$ ), obesity (AOR $2.02 \mathrm{p} \leq 0.01$ ), no use of antibiotic (AOR $1.41, \mathrm{p} \leq 0.01)$ and high parity $(>4),($ AOR $1.18 ; \mathrm{p}=0.04)$. Similar to our findings a significant association between the occurrence of SSI and blood loss was reported by Molla et al (AOR 2.21; $\mathrm{p}=0.01$ ). ${ }^{15}$ Also, these results were supported by Wodajo et al and Davidson et al. ${ }^{12,16}$ This could be explained by the fact that substantial blood loss and anaemia reduce immunity and increase the risk of infection by reducing macrophage activity and slowing wound healing. ${ }^{1}$ Similar to our findings, Lake et al found in a large multi-center study that the risk factors which were associated with SSI were blood loss, prolonged operative time, diabetes mellitus, and obesity. ${ }^{9}$ Also, Young et al found that obesity (BMI $\geq 30 \mathrm{~kg} / \mathrm{m}^{2}$ ), high blood loss, and transfusion were associated with SSI postabdominal hysterectomy. ${ }^{17}$ On the other hand, others reported that obesity was not a risk factor for SSI after gynecologic surgery. ${ }^{18}$ In addition, Pathak et al found that elder age, obesity, prolonged duration of surgery, medical diseases and no use of antibiotics were risk factors for SSI post-gynecologic surgery. ${ }^{5}$ Furthermore, a large study by Mahdi et al reported that medical diseases including obesity and diabetes in addition to respiratory infection, poor nutrition and low socio-economic status were risk factors identified for SSI. ${ }^{13}$
It has been reported that longer operative time is associated with complicated surgery. ${ }^{13}$ The relation between longer surgical duration and risk for SSI may be explained by the occurred tissue trauma by instrumentation and manipulation, increased blood loss, environmental pathogens contamination in addition to the decreasing the effective dose of the antibiotics with time.4,13 Also, Morgan et al found that the longer operative time is associated with increased risk of SSI after hysterectomy. ${ }^{19}$

The pre-operative antibiotic prophylaxis is recommended for hysterectomies, induced abortions, and urogynacological procedures. ${ }^{1}$ A large study (included 30 prospective randomized clinical trials and 4 metaanalyses) revealed that using prophylactic antibiotics reduces SSI and decreases the duration of hospital stay in women undergoing hysterectomy. ${ }^{20,21}$ Diabetes is significantly associated with SSI post-gynecological operations and this risk is estimated by 1.54 times in hysterectomies. ${ }^{6,9}$ This may be explained by diabetic patients had poor glycemic control and also had many comorbidity such as malnutrition, obesity and metabolic derangements. ${ }^{6}$ It has been reported that good glycemic control is associated with lower rates of SSI even in patients who do not have a preoperative diagnosis of diabetes mellitus. ${ }^{1}$ The very long study period (5-years) and the comparatively large number of participants are both strengths of this study. Among its limitations, the inability to incorporate information on the microbiological profile of SSI. Further larger studies are needed to support our results.

\section{CONCLUSION}

After gynecological surgeries, the total incidence of SSI was $4.67 \%$, and after hysterectomy, it was 7.57 percent. SSI is complex, and there were numerous major risk factors for SSI e.g., blood loss followed by prolonged duration of surgery, diabetes mellitus, obesity, no use of antibiotics and high parity (>4). In the light of our findings, the obtained rate could give a picture for SSI postgynecological operations in our country and identifying these risk factors is crucial for risk stratification of SSI and prioritizing interventions to improve the outcome.

\section{ACKNOWLEDGMENTS}

Authors would like to thanks to professors Mohamed Hany and Mohamed Abdallah for their contributions and professor Ayman Nady (chief of the department), for their invaluable assistance and suggestions during the whole process of research production.

Funding: No funding sources

Conflict of interest: None declared

Ethical approval: The study was approved by the Institutional Ethics Committee by The Minia university hospital's department of obstetrics and gynecology's (reference number: MOBGYN: 0040). 


\section{REFERENCES}

1. RCOG Practice Bulletin No. 195: Prevention of Infection After Gynecologic Procedures. Obstet Gynecol. 2018;131(6):e172-89.

2. Ekanem EE, Oniya O, Saleh H, Konje JC. Surgical site infection in obstetrics and gynaecology: prevention and management. Obstetr Gynaecol. 2021;23:124-37.

3. Pop-vicas A, Musuuza JS, Schmitz M, Al-Niaimi A, Safdar N. Incidence and risk factors for surgical site infection post-hysterectomy in a tertiary care center. Am J Infect Control. 2016;45:284-7.

4. Lachiewicz MP, Moulton LJ, Jaiyeoba O. Pelvic surgical site infections in gynecologic surgery. Infect Dis Obstet Gynecol. 2015;614950.

5. Pathak A, Mahadik K, Swami MB, Roy PK, Sharma M, Mahadik VK, Lundborg CS. Incidence and risk factors for surgical site infections in obstetric and gynecological surgeries from a teaching hospital in rural India. Antimicrob Resist Infect Control. 2017;6:66.

6. Black JD, De Haydu C, Fan L, Sheth SS. Surgical site infections in gynecology. Obstet Gynecol Surv. 2014;69(8):501-10.

7. Wright JD, Herzog TJ, Tsui J, Ananth CV, Lewin SN, Lu YS et al. Nationwide trends in the performance of inpatient hysterectomy in the United States. Obstet Gynecol. 2013;122(2 0 1):233-41.

8. Steiner HL, Strand EA. Surgical-site infection in gynecologic surgery: pathophysiology and prevention. Am J Obstet Gynecol. 2017;217(2);1218.

9. Lake AG, Mcpencow AM, Dick-Biascoechea MA, Martin DK, Erekson EA. Surgical site infection after hysterectomy. Am J Obstet Gynecol. 2013;209(5):490e1-9.

10. Bakkum-Gamez JN, Dowdy SC, Borah BJ, Haas LR, Mariani A, Martin JR et al. Predictors and costs of surgical site infections in patients with endometrial cancer. Gynecol Oncol. 2013;130(1):100-6.

11. Mangram AJ, Horan TC, Pearson ML, Silver LC, Jarvis WR. Guideline for Prevention of Surgical Site Infection, 1999. Centers for Disease Control and Prevention (CDC) Hospital Infection Control Practices Advisory Committee. Am J Infect Control. 1999;27:97-132.

12. Davidson C, Enns J, Bennett C, Sangi-Haghpeykar H, Lundeen S, Eppes C. Reducing abdominal hysterectomy surgical site infections: A multidisciplinary quality initiative. Am $\mathrm{J}$ Infect Control. 2020;48(11):1292-7.
13. Mahdi H, Goodrich S, Lockhart D, Debernardo R, Moslemi-Kebria M. Predictors of surgical site infection in women undergoing hysterectomy for benign gynecologic disease: a multicenter analysis using the national surgical quality improvement program data. $\mathrm{J}$ Minim Invasive Gynecol. 2014;21(5):901-9.

14. Uppal S, Harris J, Al-Niaimi A, Swenson CW, Pearlman MD, Reynolds RK et al. Prophylactic Antibiotic Choice and Risk of Surgical Site Infection After Hysterectomy. Obstet Gynecol. 2016;127(2):321-9.

15. Molla M, Temesgen K, Seyoum T, Melkamu M. Surgical site infection and associated factors among women underwent cesarean delivery in Debretabor General Hospital, Northwest Ethiopia: hospital based cross sectional study. BMC Pregnancy Childbirth. 2019; 19:317.

16. Wodajo S, Belayneh M, Gebremedhin S. Magnitude and Factors Associated with Post-Cesarean Surgical Site Infection at Hawassa University Teaching and Referral Hospital, Southern Ethiopia: A Crosssectional Study. Ethiop J Health Sci. 2017;27(3):28390.

17. Young H, Bliss R, Carey JC, Price CS. Beyond core measures: identifying modifiable risk factors for prevention of surgical site infection after elective total abdominal hysterectomy. Surg Infect (Larchmt). 2011;12(6):491-6.

18. Chen CC, Collins SA, Rodgers AK, Paraiso MF, Walters MD, Barber MD. Perioperative complications in obese women vs normal-weight women who undergo vaginal surgery. Am J Obstet Gynecol. 2007;197:98-e1-8.

19. Morgan DM, Swenson CW, Streifel KM, Kamdar NS, Uppal S, Burgunder-Zdravkovski L et al. Surgical site infection following hysterectomy: adjusted rankings in a regional collaborative. Am J Obstet Gynecol. 2015;214(4):P259.E1-E8.

20. Van Eyk N, Van Schalkwyk J. Antibiotic prophylaxis in gynaecologic procedures. J Obstet Gynaecol Can. 2012;34(4):382-91.

21. Ayeleke RO, Mourad S, Marjoribanks J, Calis KA, Jordan V. Antibiotic prophylaxis for elective hysterectomy. Cochrane Database Syst Rev. 2017;6(6):CD004637.

Cite this article as: Goma K, El Gelany S, Galal AF. Incidence and risk factors for surgical site infection post-gynecological operations in a tertiary hospital in Egypt: a retrospective study. Int J Reprod Contracept Obstet Gynecol 2022;11:299-303. 